\title{
Micromechanics in biogenic hydrated silica: hinges and interlocking devices in diatoms
}

\author{
I C Gebeshuber ${ }^{1,2 *}$ and R M Crawford ${ }^{3}$ \\ ${ }^{1}$ Institut für Allgemeine Physik, Vienna University of Technology, Wien, Austria \\ ${ }^{2} \mathrm{AC}^{2} \mathrm{~T}$ Austrian Center of Competence for Tribology, Wiener Neustadt, Austria \\ ${ }^{3}$ Alfred-Wegener Institute for Polar and Marine Research, Bremerhaven, Germany
}

The manuscript was received on 3 November 2005 and was accepted after revision for publication on 10 August 2006.

DOI: $10.1243 / 13506501$ JET163

\begin{abstract}
Diatoms are single-celled organisms with rigid parts in relative motion at the micrometre scale and below. These biogenic hydrated silica structures have elaborate shapes, interlocking devices, and, in some cases, hinged structures. The silica shells of the diatoms experience various forces from the environment and also from the cell itself when it grows and divides, and the form of these micromechanical parts has been evolutionarily optimized during the last 150 million years or more, achieving mechanical stability. Linking structures of several diatom species such as Aulacoseira, Corethron, and Ellerbeckia are presented in high-resolution SEM images and their structure and presumed functions are correlated. Currently, the industry for micro- and nanoelectromechanical devices (MEMS and NEMS) puts great effort into investigating tribology on the micro- and nanometre scale. It is suggested that micro- and nanotribologists meet with diatomists to discuss future common research attempts regarding biomimetic ideas and approaches for novel and/or improved MEMS and NEMS with optimized tribological properties.
\end{abstract}

Keywords: biotribology, diatom tribology, biogenic hydrated silica structures in relative motion

\section{INTRODUCTION}

Diatoms are single-celled organisms that generally multiply by cell division (see reference [1] for a general introduction). The oldest recorded diatom fossil dates back to 180 million years [2]. One of the best-known properties of the diatom cell is that it is contained in a shell of amorphous hydrated silica, $\mathrm{SiO}_{2} \cdot 2 \mathrm{H}_{2} \mathrm{O}$. The silica is biomineralized in the sense that it is produced by the organism, probably in a colloidal form and not incorporated from the environment. More than 50 different minerals are produced by organisms [3]. The biogenic glass of the diatoms is formed in exquisite detail even at the nanometre scale.

The cell wall of the naturally nanostructured diatoms is in essence composed of two halves that

\footnotetext{
${ }^{*}$ Corresponding author: Institut für Allgemeine Physik, Vienna University of Technology, Technische Universitaet Wien, Wiedner Hauptstrasse 8-10/134, Wien A-1040, Austria. email: ille@iap. tuwien.ac.at or gebeshuber@iap.tuwien.ac.at
}

overlap, as do the two halves of a Petri dish or a shoe box [Fig. 1(a)]. The parts of the silica box tightly fit into each other and protect the protoplast (i.e. the living protoplast including its membranes) from being twisted or squeezed. The silica box is of great relative strength [4], thus protective and transparent and thereby allowing light to pass through to the chloroplasts for photosynthesis. The pores of the silica box are thought to allow for material exchange with the environment [5]. During growth of the cell, the two halves are pushed away from each other as the protoplasm expands [Fig. 1(b)]. The silica parts also move against each other during cell division. After the nucleus divides, the cytoplasm pinches in two and results in two cells within the old cell wall with each lying up against one of the old walls [Figs 1 (c) and (d)]. Within a membrane sac on the other side of each new cell, a new half of the wall (a valve, $\mathrm{V}$ ) is then formed, each of them back to back with the other. Thereby, each of the two new cells has one old and one newly built valve. In many cases, the surfaces of these new valves are relatively 


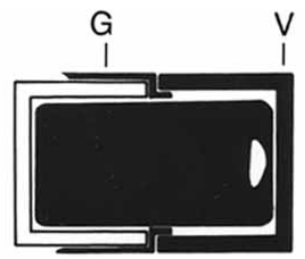

b

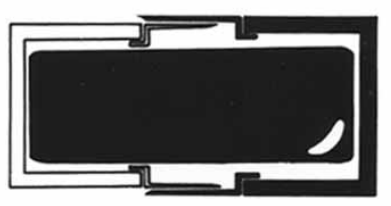

C

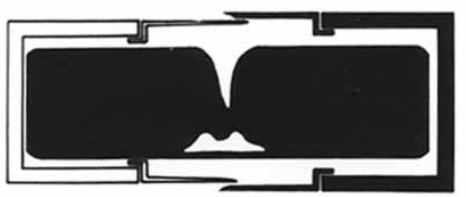

d

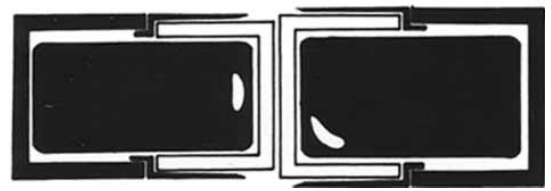

Fig. 1 Schematic of cell division in diatoms. (a) A single diatom cell, with two valves $(\mathrm{V}$, one in black and one in white) and one series of girdle bands (G). (b) As the protoplasm expands during growth of the diatom, the two valves are pushed away from each other and an additional series of girdle bands are produced to accommodate the larger volume. (c) First the nucleus and then the cytoplasm divides to produce (d) two new cells. The new valves are formed, back-to-back with another. Each of the two new cells has one old and one newly built valve

smooth and when the walls are fully silicified, they are released from their membrane sac and the two new cells drift apart. Often, though, the valve surface is full of folds and spines but each component is always a discrete one within its single membrane sac until maturity when it is released from the vesicle. In addition to the valves, there are girdle bands (G) of silica surrounding the middle of the cell between the two valves on each cell and shown as one component on each valve in Fig. 1. These bands are to protect the protoplast during cell expansion before division [6]. The girdle bands are also produced in their own individual vesicles, but this will not concern us further here [1].

Diatoms occur both in freshwater and in seawater and may be attached to surfaces or freely floating. In many cases, the diatoms form colonies. This has been perceived a device for slowing the sinking rate of the cell(s) in the water column [7], but it has recently been suggested as an anti-dispersion strategy [8]. Most of the diatom colonies are chains in which the single cells are connected end on end (valve to valve) like a string of pearls. Diatom colonies often comprise $30-50$ cells. The valve-to-valve connection of the diatoms in a colony leaves the girdle band surface unaffected and able to function to accommodate cell expansion.

The cells manage to form these chains in one of two ways: either with biogenic adhesives connecting the single cells or via mechanical attachments. The adhesive material is produced by the cells through the sister or sibling valves and sticks them together or to a substratum. Such adhesives are common even in solitary species and can, for example, create problems through the fouling of the hulls of ships $[\mathbf{9}, \mathbf{1 0}]$. Some of the diatom adhesives are very strong and reveal self-healing properties, i.e., broken adhesive bonds rebond when the adhesive is not stressed for a period exceeding a few seconds [11]. They might serve as templates for engineering novel underwater adhesives $[\mathbf{1 1}, \mathbf{1 2}]$. The colony formation by adhesion will concern us no more here.

In the case of mechanical attachments between the single cells forming a chain, the cells produce linking structures that are integral with the valve and must, therefore, be formed within its membrane vesicle. In other words, the two sets of spines are formed simultaneously in the linking position. The sibling cells will remain in this relationship until, by some accident, the cells and/or the spines are broken. These mechanical linking structures are so well engineered and tight that the spines may remain interlocked even when the cells die, as can regularly be seen in specimens from diatom fossil deposits millions of years old [1]. Chain formation by linking structures must deal with two potentially destructive forces: one that threatens to pull the cells apart from one another and another that works to twist the chain. There is also the possibility of wear and abrasion of the interacting linking structures. Depending on the specific growth situations of the cells, the silica shells may be threatened by damage and wear, especially in turbulent inshore marine waters or in fast flowing streams and waterfalls. In the very nature of their formation, the valves and girdle bands cannot be replaced or restored once they are released from the membrane sacs in which they are formed and so they have evolved technologically interesting micromechanical solutions to such problems.

The following sections will present several examples of interlocking devices and hinges in diatoms. Historically interested readers might also 
wish to read 'Art forms in nature' (1st edition 1899) [13] and 'On growth and form' (1st edition 1917) [14], especially chapter V on biomineralized structures and chapter VIII on form and mechanical efficiency.

\section{HINGES AND INTERLOCKING DEVICES IN DIATOMS}

It is known from the fossil record that colony formation by means of linking structures has a long history in the diatoms. Whereas linking by adhesives cannot be proved from fossil samples (since the adhesives disintegrated long ago), there are many examples of sister valves remaining attached through linking structures even in fossil deposits as many as 50 million years old. The diatoms are believed to have originated in the sea because the earliest deposits containing diatoms are marine [1]; what must have been a silica-rich environment seems to have favoured the development of extremely thick cell walls and the Ellerbeckia illustrated here is not exceptional with a cell wall thickness of $3-4 \mu \mathrm{m}$; $0.1-0.2 \mu \mathrm{m}$ is more usual for some modern planktonic species.

The linking structures formed by many of the diatom species common in these times were massive, but they were not simple (discussed subsequently). Nowhere a simple hook and loop arrangement is seen that one finds in a toy train coupling that has to permit sinusoidal movement as the train negotiates curves but does not normally have to deal with forces or moments that would twist the train. The linking arrangements in diatoms reduce the degrees of freedom, either to two as in the toy train or to one or even zero, as would be more likely in the turbulent ocean. The authors do not intend to review linking structures throughout the diatoms but to present instructive examples to illustrate some ways in which the diatom cell wall is equipped to deal with potentially destructive forces and moments.

For microelectromechanical systems (MEMS) and nanoelectromechanical systems (NEMS) technologies, macroscopic best practice in terms of, for example, lubrication and surface topography cannot be scaled down linearly. Effects of adhesion, stiction,* and contamination by third bodies, which are swamped by bulk continuum phenomena at the macroscale, become dominant at the micrometre length scale. Currently, the MEMS and NEMS

\footnotetext{
* Stiction refers to the tendency of read/write heads of hard disk drives to stick to the platters, preventing the disk from spinning up and possibly causing physical damage to the media [15]. The word is a combination of 'static' and 'friction'.
}

industry puts great effort into investigating tribology on the micro- and nanometre scale. Novel threedimensional MEMS such as piezoelectric inkjet printer parts, accelerometers in cars for airbag deployment in collisions, gyroscopes used in modern cars to trigger dynamic stability control, disposable blood pressure sensors, or the several hundred thousands of digital micromirrors in a beamer would exhibit increased performance as soon as their tribology were optimized.

Diatoms already have well adapted and elaborate tribological properties on these scales and, therefore, can provide valuable ideas and templates for optimized MEMS and NEMS.

\section{OBSERVATIONS}

As a generalization, sibling valves of diatoms in a colony may either be joined at the centre of the valve face or at its margin. Good examples of the latter can be found in the plankton where organisms are free-floating in the lake or ocean. The genus ${ }^{\dagger}$ Aulacoseira (two sibling valves with T-shaped interconnections shown in Fig. 2), which is cylindrical with a discoid valve face, has a complete ring of spatulate spines, reducing the degrees of freedom of movement between the sibling valves to zero.

Similar spines are found along part of the margin of some species of the freshwater Fragilaria and in some genera of the marine Cymatosiraceae, all genera with somewhat oval or even spindle-shaped valves (see Fig. 3 for the elaborate spines between the two valves of the single cells). In the common marine genus Skeletonema, again a perfect cylinder, the marginal spines take a different form with a complex three-dimensional linkage. In all of these cases, there is no other structure on the valve face that links the cells together. In Skeletonema (see Fig. 4(a) for a colony of several cells and Fig. 4(b) for a zoom into the linking structures), there is a large space between the cells, that must be filled with seawater, as no organic material has ever been observed here. The authors propose that even in the most tightly bound siblings, e.g. Aulacoseira, water provides lubrication between interfacing structures of the two sibling valves. Fragilaria and Cymatosira would be intermediates in this respect.

\footnotetext{
${ }^{\dagger}$ A genus (plural genera) is a grouping in the classification of organisms comprising one or more species. In the common biological nomenclature in the convention of Linneaus, the name of an organism is composed of two parts - the binomial: its genus (always capitalized) and a species modifier. An example is Homo sapiens, the name for the human species that belongs to the genus Homo.
} 


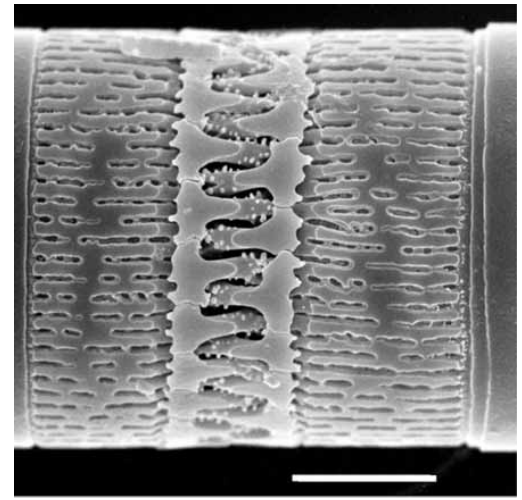

Fig. 2 Examples of linking sibling valves in the diatoms: in the freshwater genus Aulacoseira, sibling valves are often joined to form chains at the margin of the valve face by spatulate (T-shaped) spines, which, in some cases, seem to be able to allow the sibling valves to move apart a little, scale bar $=5 \mu \mathrm{m}$

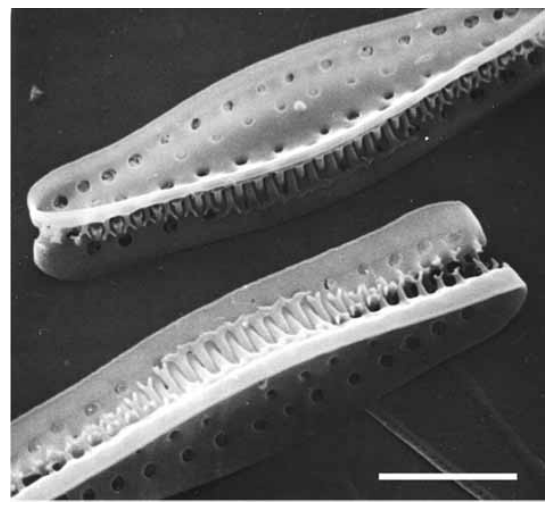

Fig. 3 In the genus Cymatosira, the cells also form chains but can live as single cells. The two valves of the single cells are connected via elaborated spines. Scale bar $=10 \mu \mathrm{m}$.

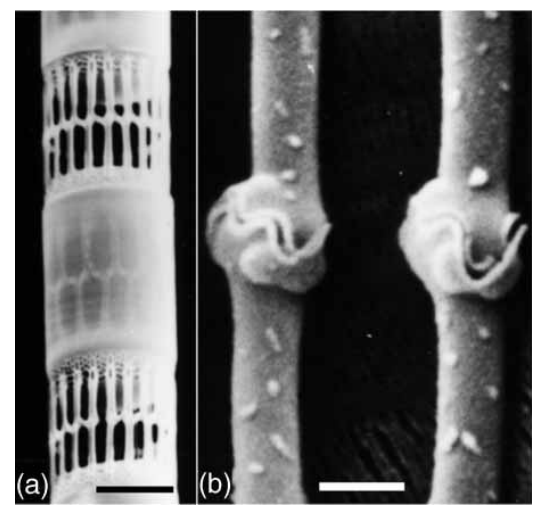

Fig. 4 In the common marine planktonic genus Skeletonema, the cells are held in chains by spines that maintain a wide gap between cells (a) and link by complex junctions of the spines (b). Scale bar, $a=50 \mu \mathrm{m}, b=5 \mu \mathrm{m}$

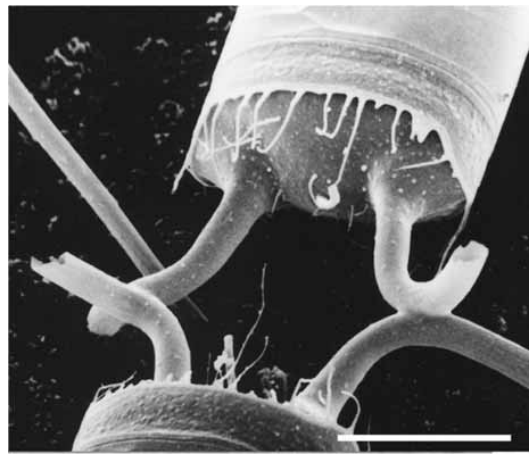

Fig. 5 The sibling valves of, perhaps, the most common marine planktonic diatom Chaetoceros are fused along part of their setae. Scale bar $=50 \mu \mathrm{m}$

Perhaps, the most common marine planktonic diatom genus is Chaetoceros, some species of which form chains and do so by fusion of the so-called setae between sibling valves. The seta is a kind of horn projecting out as a tube from the valve surface, usually one each at opposite ends of a slightly bipolar valve face and the fusion occurs close to, or a little distance from, the valve surface (Fig. 5). Because the setae grow out from the two sibling valves together, it is imagined that when they meet, the membrane sacs fuse with each other, allow the fusion of silica, and then, as the setae continue their different directions, become separated again; an example of the exquisite control that these organisms have. In all of these cases of chain formation, there exists the ability of the diatom to discontinue the chain by forming sibling valves that lack the linking structures [16], but this need not concern us further here.

If the diatoms from the fossil record are examined, it is apparent that much evolutionary experimentation took place in the early days when most of the diatoms were, at least fundamentally and approximately, radially symmetrical in valve view.* One of the experiments concerned linking sibling valves by means of a structure at the centre of the valve. Syndetocystis is a beautiful example (Fig. 6 shows the valve of one cell, the interconnection to the other cell, and a part of the second cell - the rest of that valve broke off sometime during the last 50 or so million years, Fig. 7 gives a detailed view of the linking structure). This diatom genus is heavily silicified and has a long tube at the centre of each valve that extends way beyond the valve and terminates in a two-armed clasp that loops around

\footnotetext{
* Note that the term 'radial symmetry' in biology is used differently than in engineering or mathematics. In the language of biology, organisms with radial symmetry may have body parts arranged in a regular, repeating pattern around a central axis (i.e. they are symmetric with respect to rotations of $2 \pi / n$ )
} 


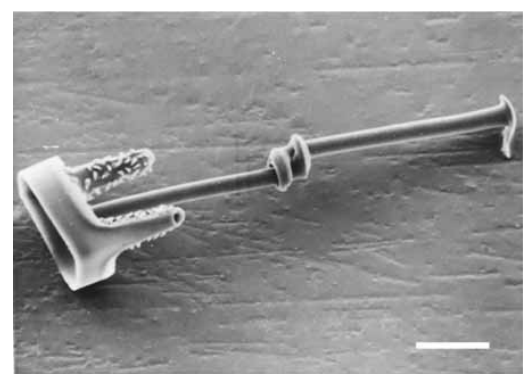

Fig. 6 In the fossil genus Syndetocystis, the linking occurs by means of a structure at the centre of the valve. One of the valves has been broken and lost. At the apex of each spine is a loop that surrounds the shaft of the other spine. Scale bar $=20 \mu \mathrm{m}$

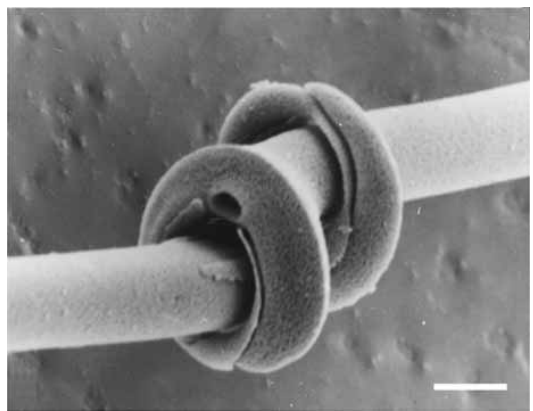

Fig. 7 A detail of the apex is shown. Scale bar $=5 \mu \mathrm{m}$

the tube from the sibling valve. By its very nature, each clasp is asymmetric and this asymmetry confers stability by preventing twisting of either valve with respect to its sibling.

Another fossil genus, Trochosira, has a different arrangement. A large fluted spine from one sibling (Fig. 8) fits tightly inside three smaller spines from the other sibling (Fig. 9). It is clear that twisting was

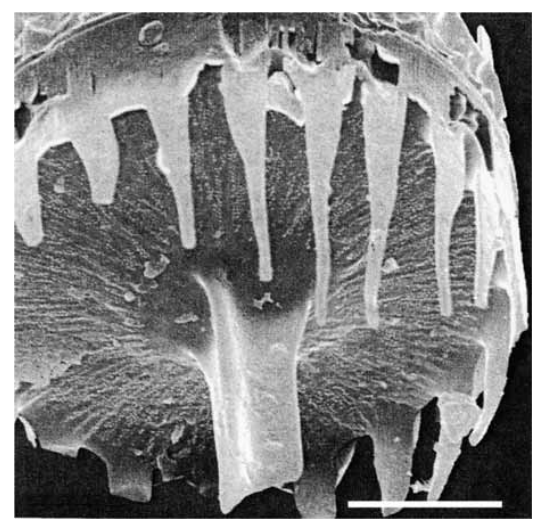

Fig. 8 In the fossil genus Trochosira, the linking occurs by means of a large fluted spine at the centre of the valve

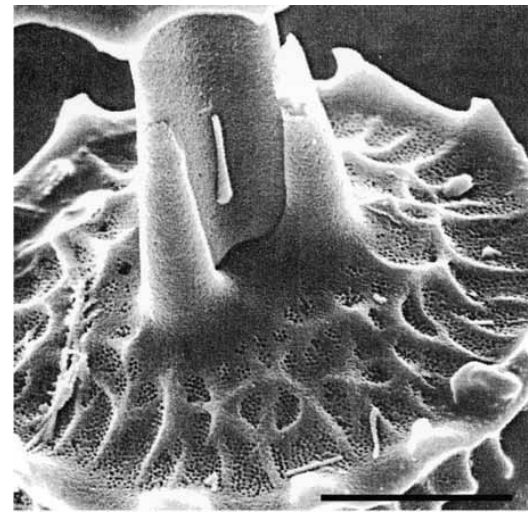

Fig. 9 The spine of Trochosira fits tightly inside three smaller spines from the other sibling. Scale bar $=50 \mu \mathrm{m}$

prevented, but it is not easy to understand how the valves stayed together.

A genus with a good fossil record and, unusually, with species living today in both marine and freshwater habitats is Ellerbeckia. It has very closely linked sibling valves united by complex linking systems (Fig. 10). The valve margin of most species has very elaborate linking spines (Fig. 11), but there are also linking structures on the valve face, more or less towards the valve centre and usually radially orientated. Some examples are given in Figs 12 and 13 (the upper valves in both images are broken to expose the linking structures). In many species, one of the two sibling valves is a cameo form and the other intaglio, i.e. where the structure is either raised from or depressed into the valve surface, respectively. The two fit very closely with each other and may have the finest of detail on their surfaces - remember that they are formed in this relationship in their respective membrane sacs.

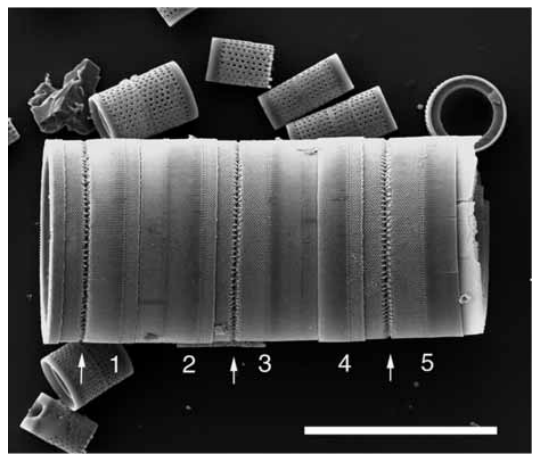

Fig. 10 A chain of what appears to be three cells of the fossil species Ellerbeckia. In reality, there are five cells (numbered) and the junctions between three sibling pairs are arrowed. Valves of Aulacoseria in the background. Scale bar $=10 \mu \mathrm{m}$ 


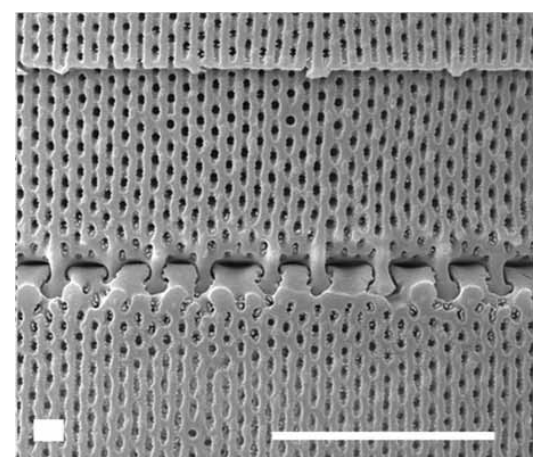

Fig. 11 A detail of the sibling junction rotated by $90^{\circ}$. Scale bar $=5 \mu \mathrm{m}$

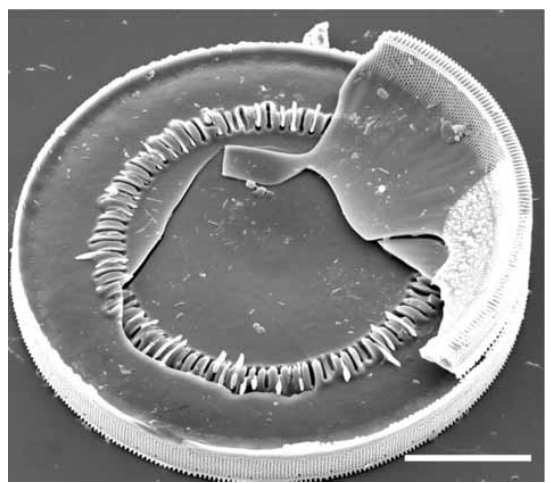

Fig. 12 A broken sibling pair of valves showing linking structures on the face of the valve. Scale bar $=20 \mu \mathrm{m}$

Figure 14 shows another species of Ellerbeckia with tightly interwoven linking structures.

At the end of chains of these two genera, one finds the so-called separation valves (Fig. 15). Formed as sibling pairs, they separate because they lack the firm linking structures on the valve margin and on

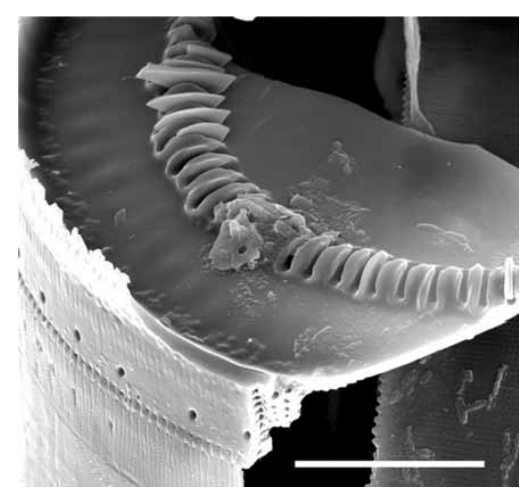

Fig. 13 Detail of another broken valve showing the intaglio slits into which the cameo ridges fit - some have broken and remain in the slits. Note the broken linking structures at the rim of the valve. Scale bar $=5 \mu \mathrm{m}$

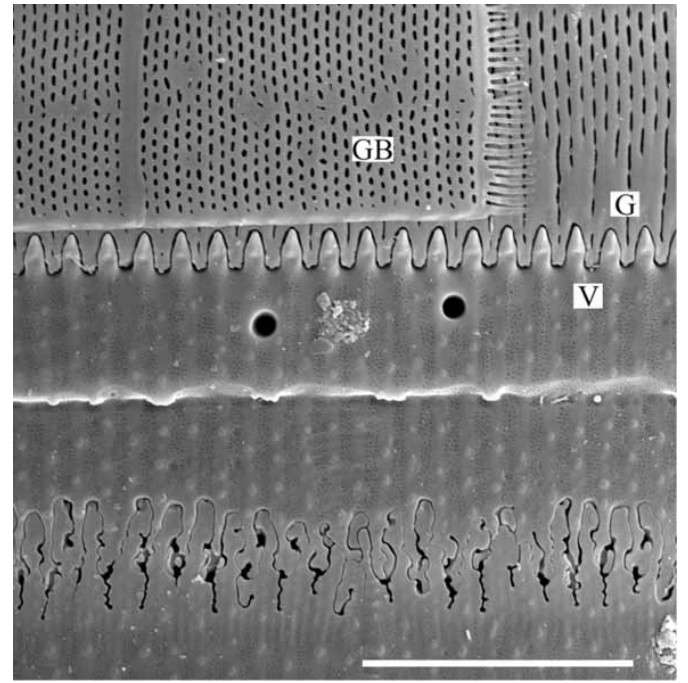

Fig. 14 Detail of another Ellerbeckia species with linking structures between valves below and interdigitating surfaces of valve edge $(\mathrm{V})$ and girdle band (G) above. Also visible are the openings of two major tubes through the valve, the porous surface covering of the valve itself and the loose girdle band (GB). The linking structures can be seen at the broken edge of the valve in Fig. 13. Scale bar $=5 \mu \mathrm{m}$

the valve face but, even here, there are cameo and intaglio structures that may be similar in form and orientation to the radial features.

It is easy to appreciate that there is no likelihood that the cells of a chain of Ellerbeckia will twist against

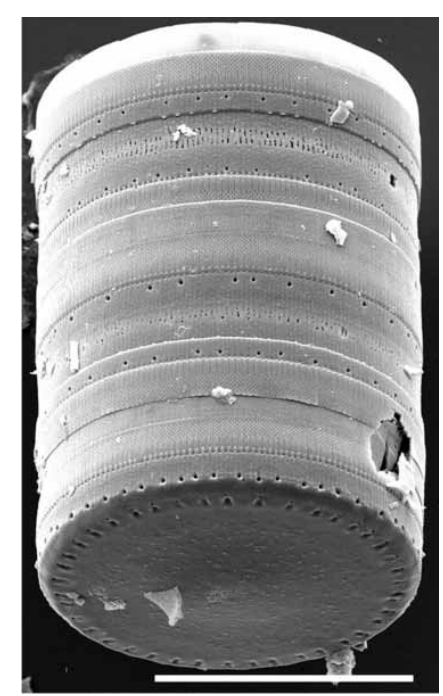

Fig. 15 A short chain with a separation valve, lacking the linking structures, at the near end. Scale bar $=25 \mu \mathrm{m}$ 


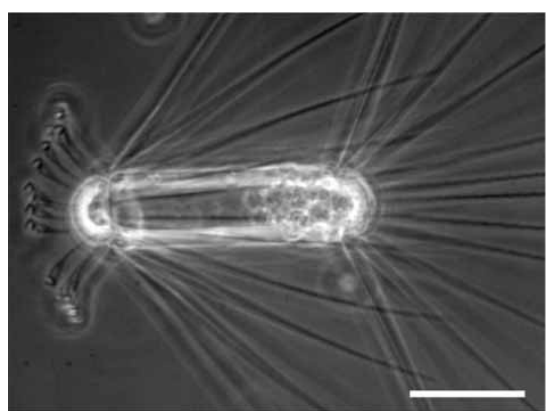

Fig. 16 A whole cell of the marine planktonic Corethron with two types of valves, one at either end of a long cylinder of girdle bands. The valve to the right has a radiating series of long spines. The valve to the left has long spines too, but also a crown of hooked spines. Scale bar $=50 \mu \mathrm{m}$

each other, yet this could be a problem for a less robust diatom. Corethron is a good example and something of an exception among diatoms. All three species have valves with movable parts and two of them exist as single cells. The cell in both of these species has two different valves. One has a set of long spines that are attached to the valve at a series of sockets on the rim of the hemispherical valve (Figs 16 to 18). The other valve also has a ring of similar spines, but alternating with them around the valve is a series of finer hooked spines (Fig. 16). Both series are inserted at their base in sockets as in the other valve. All spines can move to a degree in the socket, but the position in which they are found in the mature, independent cell is not where they are formed. The process of new valve formation in these diatoms is complicated and has been detailed in reference [6]. Put simply, the three sets of spines have to be formed along with the new valves, within, and protected by the cylinder of the two sets of girdle bands (Fig. 17). During the cell division cycle, the cell elongates greatly, forming very many girdle bands as it does so, thus creating a long space between the two sibling cells when they are complete. This space can accommodate the formation of the long spines. When the new cells are mature, they expand and pull the girdle cylinder away from the base of the spines and allow the spines to swing out to adopt their final position. In doing this, they move past a click-stop that prevents them moving too far back from their 'required' position. The whole structure is beautifully engineered in miniature but there is more. A function can be invoked for the long spines, not for hooking cells together in the marine plankton - their tiny barbs face the wrong way - but for keeping cells apart. This would be a strategy that could benefit a photosynthetic organism for which sinking out of the photic zone (i.e. the

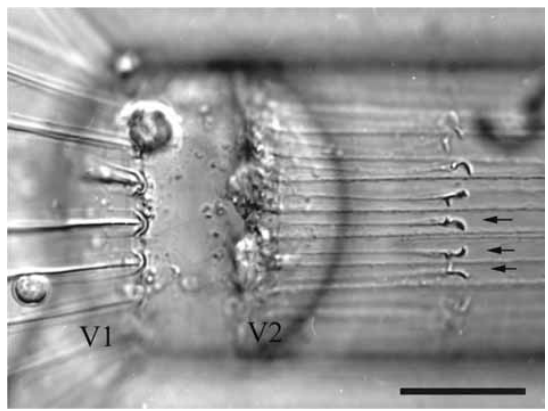

Fig. 17 A cell of Corethron with the old valve (V1) to the left showing the base of a number of long spines and the new valve (V2) to the right. Beneath the cylinder of the girdle bands, the tips of six hooked spines can be seen more or less regularly alternating with the long spines from both new valves. Note that the hooks are turned in different directions (arrows). Scale bar $=20 \mu \mathrm{m}$

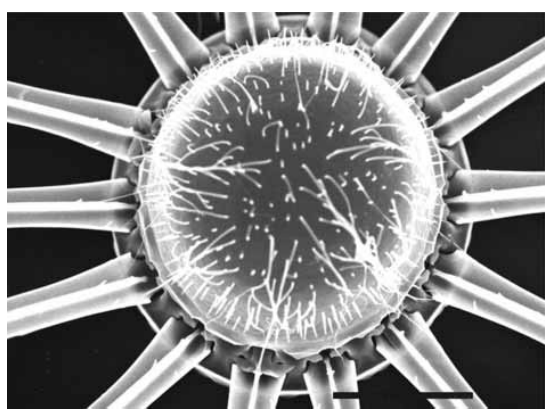

Fig. 18 Surface view of a valve similar to that in the right in Fig. 17, showing insertion of the long spines at the edge of the valve. Scale bar $=10 \mu \mathrm{m}$

surface zone of the sea or a lake having sufficient light penetration for photosynthesis) as marine snow* could be a problem. This hypothesis seems reasonable but what about the hooked spines? Figure 19 shows a number of spines in detail from Corethron pennatum. Careful inspection shows that the two surfaces of the spine are different and that there are left- and right-facing versions of the spines. On both species, the spines expand distally to form two hooks, the form of which is one of the distinguishing features of each species, and on each of the hooks, there is a series of small bead-like serrations. Without any proof, it is speculated that the function of these hooked spines is to lock the long

\footnotetext{
* In the deep ocean, marine snow is a continuous shower of mostly organic detritus falling from the upper layers of the water column. Its origin lies in activities within the productive photic zone.
} 


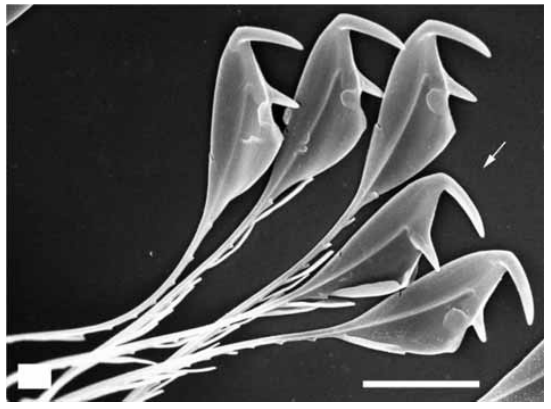

Fig. 19 Tips of five hooked spines. Note that on four of them, the second hook lies at the back and that the fifth (arrow) is, therefore, a mirror image of the others. Scale bar $=10 \mu \mathrm{m}$

spines in place beneath the girdle bands until, on maturity of the whole pair of sibling valves, the spines are allowed to swing out. It is thought [17] that the newly formed spines are spring-loaded within their sockets and that if they were released early, they would swing out and break the girdle bands. This would prevent further cell divisions. Some circumstantial evidence for this comes from light microscopy. Scanning electron microscopy shows that there are right- and left-facing versions of the hooked spines (Fig. 19). Using the inverted light microscope, the cell has been viewed from the end [6] and it appears that the direction in which the spines lie varies irregularly around the valve. However, one cannot be certain from scanning electron micrographs which way these are facing before being released from the girdle bands simply because it cannot be seen through the bands. Bearing in mind the dangers of twisting to the cell, this would seem to be in accord with the idea that, in which ever direction the cell is caused to twist, the hooked spines would remain in the locked position (Fig. 17). If they were all facing in the same direction, the entire arrangement might be vulnerable.

\section{DISCUSSION}

The diatoms are a remarkable group of organisms because they show a seemingly inexhaustible variation in the morphology of the cell wall and have a rich fossil record of evolutionary experimentation over more than 100 million years. Much of the evidence for the variation has inevitably been lost, but there is still an abundance of structure waiting to be understood. A more detailed review of the diatoms with respect to the principles outlined earlier will appear elsewhere, but here is considered the aspect of morphology as it relates to function.
There is much circumstantial evidence pointing to the likely function of this or that organelle, ${ }^{*}$ because the diatoms have occupied so many of the available ecological niches. The most obvious of these is the tendency of some genera to form chains. Not every species in a given habitat forms chains, others have different thrival strategies, but many do so in the marine intertidal and shallow inshore waters typical of those in which the diatoms are thought to have evolved. Such situations are highly dispersive, and it can be supposed that the formation of chains is simply a means to avoid dispersal. During such periods when sea levels rose and the oceans deepened [18], the plankton developed less-heavily silicified cells able to remain suspended in the surface waters. Here, the environment is not so agitated but the dispersion out of the photic zone is a problem. Many organisms are taken permanently out of this zone in the form of aggregates commonly known as 'marine snow', but the two single-celled forms of Corethron appear to have a mechanism that must significantly reduce this danger. Most interesting is that the third species of the genus forms chains. This fact encourages us to ask how could a thrival strategy in related species of the same genus be so different? This cannot be answered at present but the genus, indeed the group as a whole, shows the kind of variation in morphology that the diatoms are capable of in response to the environment. The authors need to find a way to test some of these proposals. The responses on the part of the diatoms to the problem of forming colonies (essentially chains) have been appreciated for a number of years, but the realization that a number of these structures may have evolved to counter twisting of the chain is published here for the first time.

Finally, tribologists will wonder at the possibilities of erosion of the structure of the different wall components as they move tightly against one another. This is a subject that has received no attention in the diatoms because moving components have not been recognized as such and chains of cells have not been considered with respect to the forces acting on them. It was pointed out above that the wall components are formed by silicification within an organic membrane vesicle. The fate of the membrane, to the inside and to the outside of the component when the latter is completed, is a matter for debate, but it seems that the outer profile is lost. The wall thus comes to lie on the biological outside of the cell, and, if the diatom forms chains, there will be nothing between it and the sibling,

\footnotetext{
*An organelle is a structure which occurs in cells and which has a specialized function.
} 
valve except the outside medium, water. If water is necessary to provide a lubricating cushion between the two siblings, then the authors might expect even the tightest fitting of species to show some way that water can get between the valve faces. It seems that all do so even if, as in Ellerbeckia, some very fine channels connect not the outside medium to the valve face but the protoplast itself.

It is suggested that micro- and nanotribologists meet with diatomists to discuss future common research attempts concerning micro- and nanomechanics of the silica structures, such as diatom wear studies. Diatoms are small, easy to cultivate, and because many of them are transparent, they are accessible to in vivo light microscopy techniques. Furthermore, some diatom species that stably adhere to a substratum are also accessible with atomic force microscopy techniques [11, 12, 19-24]. In addition, atomic force spectroscopy can yield important information on micro- and nanomechanical properties such as adhesion, viscoelasticity, hardness, and so on.

A real breakthrough in diatom tribology concerning the applicability to MEMS and NEMS requires basic understanding of the connection between structure and function of the silica walls and detailed knowledge about the chemical and physical properties at the interfaces. Furthermore, a generalization of the methods of controlled synthesis to new classes of monomers would tremendously strengthen nanotechnology $[\mathbf{2 5}, \mathbf{2 6}]$.

First publications concerning the tribology $[\mathbf{1 1}, \mathbf{1 2}$, 19-24] and the nanotechnology [27, 28] of diatoms are already available in the literature and, hopefully, soon, there will be many more.

\section{ACKNOWLEDGEMENTS}

A part of this work has been funded by the Austrian Kplus-Program via the Austrian Center of Competence for Tribology, AC2T research $\mathrm{GmbH}$, Wiener Neustadt.

The authors wish to thank K. Kaska for critically reading the manuscript and Pat Sims for kindly supplying Figs 6 to 9.

\section{REFERENCES}

1 Round, F. E., Crawford, R. M., and Mann, D. G. Diatoms: biology and morphology of the genera, 1990 (Cambridge University Press, Cambridge).

2 Rothpletz, A. Ueber die Flysh-Fucoiden und einige andere fossile Algen, sowie ueber liasische, Diatomeen fuehrende Hornschwamme. Zeitschr. Deutsch. Geol. Ges., 1896, 48, 910-914.
3 Mann, S. Biomineralization, 2002 (Oxford University Press, Oxford).

4 Hamm, C. E., Merkel, R., Springer, O., Jurkojc, P., Maier, C., Prechtel, K., and Smetacek, V. Architecture and material properties of diatom shells provide effective mechanical protection. Nature, 2003, 421, 841-843.

5 Pickett-Heaps, J., Schmid, A.-M. M., and Edgar, L. A. The cell biology of diatom valve formation. In Progress in phycological research (Eds F. E. Round and D. J. Chapman), 1990, vol. 7, pp. 1-168 (Biopress, Bristol).

6 Crawford, R. M., and Hinz, F. The spines of the centric diatom Corethron criophilum: light microscopy of vegetative cell division. Eur. J. Phycol., 1995, 30, 95-105.

7 Tappan, H. and Loeblich, A. R. Jr. Evolution of the Oceanic plankton. Earth-Sci. Rev., 1973, 9, 207-240.

8 Crawford, R. M. Misleading perceptions - two illustrations of impediments to our understanding of behavioural diversity among planktonic diatoms. (Abstract). Phycologist, 2003, 64, 4.

9 Higgins, M. J., Crawford, S. A., Mulvaney, P., and Wetherbee, R. The topography of soft, adhesive diatom 'trails' as observed by atomic force microscopy. Biofouling, 2000, 16, 133-140.

10 Evans, L. V. and Hoagland, K. D. (Eds) Algal biofouling (studies in environmental science), 1987 (Elsevier Publishing Company, Amsterdam).

11 Gebeshuber, I. C., Thompson, J. B., Del Amo, Y., Stachelberger, H., and Kindt, J. H. In vivo nanoscale atomic force microscopy investigation of diatom adhesion properties. Mater. Sci. Technol., 2002, 18, $763-766$.

12 Gebeshuber, I. C., Kindt, J. H., Thompson, J. B., Del Amo, Y., Stachelberger, H., Brzezinski, M., Stucky, G. D., Morse, D. E., and Hansma P. K. Atomic force microscopy study of living diatoms in ambient conditions. J. Microsc., 2003, 212, 292-299.

13 Haeckel, E. Art forms in nature, 1974 (Dover Pictorial Archives, Dover Publications, New York).

14 Thompson, D. A. W. On growth and form, 1992 (Dover Publications, New York).

15 Mate, C. M. Molecular tribology of disk drives. Tribol. Lett., 1998, 4, 119-123.

16 Davey, M. C. and Crawford, R. M. Filament formation in the diatom Melosira granulata. J. Phycol., 1986, 22, 144-150.

17 Crawford, R. M., Hinz, F., and Honeywill, C. Three species of the diatom genus Corethron Castracane: structure, distribution and taxonomy. Diatom Res., 1998, 13, 1-28.

18 Sims, P. A., Mann, D. G., and Medlin, L. K. Evolution of the diatoms: insights from fossil, biological and molecular data. Phycologia, 2006, 45, 361-402.

19 Crawford, S. A., Higgins, M. J., Mulvaney, P., and Wetherbee, R. The nanostructure of the diatom frustule as revealed by atomic force and scanning electron microscopy. J. Phycol., 2001, 37, 543-554.

20 Gebeshuber, I. C., Stachelberger, H., and Drack, M. Diatom bionanotribology - biological surfaces in relative motion: their design, friction, adhesion, lubrication and wear. J. Nanosci. Nanotechnol., 2005, 5(1), 79-87. 
21 Higgins, M. J., Crawford, S. A., Mulvaney, P., and Wetherbee, R. Characterization of the adhesive mucilages secreted by live diatom cells using atomic force microscopy. Protist, 2002, 153, 25-38.

22 Higgins, M. J., Molino, P., Mulvaney, P., and Wetherbee, R. The structure and nanomechanical properties of the adhesive mucilage that mediates diatomsubstratum adhesion and motility. J. Phycol., 2003, 39, $1181-1193$.

23 Higgins, M. J., Sader, J. E., Mulvaney, P., and Wetherbee, R. Probing the surface of living diatoms with atomic force microscopy: the nanostructure and nanomechanical properties of the mucilage layer. J. Phycol., 2003, 39, 722-734.

24 Gebeshuber, I. C., Stachelberger, H., and Drack, M. Diatom tribology. In Life cycle tribology (Eds D. Dowson, M. Priest, G. Dalmaz, and A. A.
Lubrecht) Tribology and interface engineering series, Series Ed. B. J. Briscoe, 2005, vol. 48, pp. 365-370 (Elsevier, Amsterdam).

25 Seeman, N. C. and Belcher, A. M. Emulating biology: building nanostructures from the bottom up. Proc. Natl. Acad. Sci., 2002, 99, 6451-6455.

26 Zhang, S. Fabrication of novel biomaterials through molecular self-assembly. Nat. Biotechnol., 2003, 21(10), 1171-1178.

27 Gebeshuber, I. C., Pauschitz, A., and Franek, F. Biotribological model systems for emerging nanoscale technologies. Proceedings 2006 IEEE Conference on Emerging technologies - nanoelectronics, Singapore, 10-13 January 2006, pp. 396-400.

28 Gordon, R., Sterrenburg, F. A. S., and Sandhage, K. (Eds) Special issue on diatom nanotechnology. J. Nanosci. Nanotechnol., 2005, 5(1), 1-178. 